\title{
Chebyshev Bandpass Filter Using Resonator of Tunable Active Capacitor and Inductor
}

\author{
Yu Wang, Jian Chen, and Chien-In Henry Chen \\ Department of Electrical Engineering, Wright State University, Dayton, OH 45435, USA \\ Correspondence should be addressed to Chien-In Henry Chen; henry.chen@wright.edu
}

Received 13 March 2017; Accepted 24 April 2017; Published 18 May 2017

Academic Editor: Chang-Ho Lee

Copyright (c) 2017 Yu Wang et al. This is an open access article distributed under the Creative Commons Attribution License, which permits unrestricted use, distribution, and reproduction in any medium, provided the original work is properly cited.

\begin{abstract}
A classic second-order coupled-capacitor Chebyshev bandpass filter using resonator of tunable active capacitor and inductor is presented. The low cost and small size of CMOS active components make the bandpass filter (BPF) attractive in fully integrated CMOS applications. The tunable active capacitor is designed to compensate active inductor's resistance for resistive match in the resonator. In many design cases, more than $95 \%$ resistive loss is cancelled. Meanwhile, adjusting design parameter of the active component provides BPF tunability in center frequency, pass band, and pass band gain. Designed in $1.8 \mathrm{~V} 180$ nanometer CMOS process, the BPF has a tuning frequency range of $758-864 \mathrm{MHz}$, a controllable pass band of 7.1-65.9 MHz, a quality factor $Q$ of $12-107$, a pass band gain of $6.5-18.1 \mathrm{~dB}$, and a stopband rejection of $38-50 \mathrm{~dB}$.
\end{abstract}

\section{Introduction}

The rapid development of complementary metal-of-semiconductor (CMOS) endues the integrated circuit with small size and low cost in both digital and analog applications. A wireless communication system mainly consists of three components: mixer, bandpass filter, and low noise amplifier. The bandpass filter blocks unwanted signals and selects desirable signal matched to different pass band mixers, that is, $1,920-1,980 \mathrm{MHz}$ of WCDMA, $890-960 \mathrm{MHz}$ of GSM, $1,575 \mathrm{MHz}$ of GPS L1 BPF, and 2,400-2,483 MHz of $802.11 \mathrm{~b} / \mathrm{g}$. Bandpass filter with high $Q$ and good selectivity of center frequency and bandwidth is desirable in today's applications. The LC based passive bandpass filter has been used for several decades; however, when applied to the nanotechnology CMOS integrated circuit it confronts limitations. For example, the degraded performance of CMOS spiral inductor due to its significant resistive loss reduces BPF quality factor and restrains the gain and bandwidth [1,2]. Inductors are bulky and expensive, significantly increasing the instability of integration and manufacturing cost. Tunable $\mathrm{AC}$ achieves in a wide capacitive range from $40 \mathrm{fF}$ to $1 \mathrm{pF}$ $[1,3]$ and tunable AI achieves in a wide inductive range from
$1 \mathrm{nH}$ to $300 \mathrm{nH}$ [4]. Therefore, using AC and AI to produce a small size and low cost BPF with tunable gain, tunable center frequency, and tunable bandwidth is a feasible and cost-effective solution. For this reason, eliminating resistive loss in AI will improve BPF quality factor.

Reducing resistive loss in the Chebyshev bandpass filter has been presented in improvement on pass band gain, bandwidth, and center frequency $[1,2,5-8]$. The tappedinductor compensates the inductor resistive loss and adds an additional shunt feedback passive inductor to operate in the K-band [2]. The transformer-based passive inductor produces a frequency-dependent negative resistance for resistive loss compensation [8]. It operates at a center frequency of $2,368 \mathrm{MHz}$ and a bandwidth of $60 \mathrm{MHz}$. But passive inductors make area much larger than active BPFs [57]. Inserting a gyrator-C based active inductor in a resonator demonstrates BPF applications at different frequency ranges $[6,7]$. However, the BPF operating frequencies and bandwidths are not tunable. In [5] the BPF is designed to compensate frequency-dependent resistive loss for tunable center frequency. However, the complex structure consumes large area and power consumption. In [1] the BPF design incorporates an active capacitor with negative resistance 


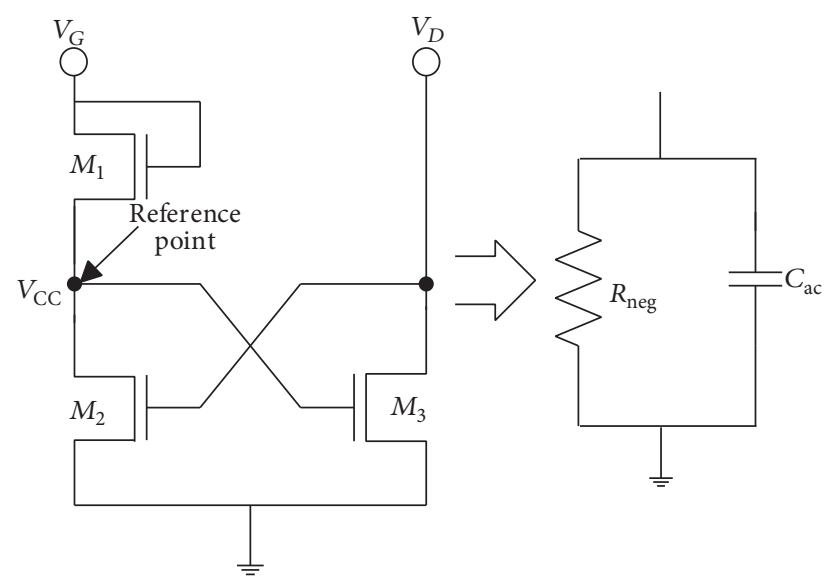

FIGURE 1: The active capacitor and its equivalent circuit.

to offset the resistive loss for large bandwidth. However, its tunability is limited due to mismatch between active capacitor's negative resistance and spiral inductor's positive resistance.

In this paper, a new BPF using tunable active capacitor and inductor is presented. Self-negative resistance of active capacitor is designed to compensate the positive resistance of active inductor, independent of signal frequency within its tunable range. Meanwhile, adjusting design parameters of the active component can control tunability of center frequency, gain, and bandwidth. The paper is organized as follows. Sections 2 and 3 discuss the principle design and operation of active capacitor and active inductor. Section 4 presents a compensation structural resonator using active capacitor and active inductor. This section also unfolds the performance of the BPF using the resonator. Finally, summary of this work and comparison with previous work are presented.

\section{Tunable Active Capacitor in BPF}

2.1. Large Signal Analysis of AC. The first active capacitor (AC) with negative resistance was demonstrated in [3]. The paper [1] adopted this AC structure and designed it in $0.18 \mu \mathrm{m}$ CMOS technology. In this section we extend the AC design principle to make it tunable and compensate resistive loss of the resonator in BPF. The active capacitor and its equivalent circuit are shown in Figure 1. The AC is designed by the crosscoupled pair of $M_{2}$ and $M_{3}$ and the resistive load $M_{1} . I_{M_{2}}$ is controlled by $V_{D}$. $V_{\mathrm{CC}}$ is determined by $I_{M_{2}}$ and $V_{G}$ and $I_{M_{3}}$ is controlled by $V_{\mathrm{CC}}$. In our design principle, we keep $V_{\mathrm{CC}}>$ $V_{D}-V_{t}$ to make $M_{2}$ in saturation and keep $V_{D}>V_{\mathrm{CC}}-V_{t}$ to make $M_{3}$ in saturation. So, $V_{D}-V_{t}<V_{\mathrm{CC}}<V_{D}+V_{t}$.

2.2. Small Signal Analysis of AC. The AC small signal model and its equivalent circuit are depicted in Figure 2. $V_{G}$ is almost the sum of $V_{\mathrm{CC}}$ and $V_{D}$ as $V_{t}$ is small and $I_{M_{1}}=I_{M_{2}}$, which expresses the relationship between $V_{\mathrm{CC}}$ and $V_{\text {in }}$. An easier way to analyze the small signal model is to set $V_{\mathrm{CC}}=\rho V_{\text {in }}$ and $\rho$ is controlled by transistor parameters.
We continue to analyze the small signal model shown in Figure 2.

$$
V_{g s_{1}}=V_{g_{1}}-V_{s_{1}}=V_{d s_{1}}=-V_{\mathrm{CC}}
$$

Therefore,

$$
-g_{m_{1}} V_{g s_{1}}=-g_{m_{1}}\left(-V_{\mathrm{CC}}\right)=g_{m_{1}} V_{\mathrm{CC}} .
$$

So, the current source $g_{m_{1}} V_{g s_{1}}$ can be flipped to opposite direction without changing the symbol. Also, $V_{g s_{2}}=V_{g s_{3}}=$ $V_{\mathrm{CC}}$. The admittance from the input port is determined by $I_{\text {in }} / V_{\text {in }}$.

$$
\begin{aligned}
I_{i_{1}} & =\left(V_{\mathrm{in}}-V_{\mathrm{CC}}\right) s C_{g d_{2}}+\left(V_{\mathrm{in}}-V_{\mathrm{CC}}\right) s C_{g d_{3}} \\
& =\left(V_{\mathrm{in}}-V_{\mathrm{CC}}\right) s\left(C_{g d_{2}}+C_{g d_{3}}\right), \\
I_{i_{2}} & =V_{\text {in }} s C_{g s_{2}}+g_{m_{3}} V_{\mathrm{in}}, \\
I_{\text {in }} & =I_{i_{1}}+I_{i_{2}} \\
& =\left(V_{\text {in }}-V_{\mathrm{CC}}\right) s\left(C_{g d_{2}}+C_{g d_{3}}\right)+V_{\text {in }}\left(s C_{g s_{2}}+g_{m_{3}}\right) .
\end{aligned}
$$

$V_{\mathrm{CC}}$ is the reference voltage shown in Figure 1. The branch currents $I_{\mathrm{O}_{1}}$ and $I_{\mathrm{O}_{2}}$ are

$$
\begin{aligned}
I_{o_{1}} & =V_{\mathrm{CC}} g_{m_{1}}+V_{\mathrm{CC}} s C_{g s_{1}}, \\
I_{o_{2}} & =V_{\mathrm{CC}} g_{m_{2}}+V_{\mathrm{CC}} s C_{g s_{3}}, \\
I_{\text {out }} & =I_{o_{1}}+I_{o_{2}} \\
& =V_{\mathrm{CC}}\left(g_{m_{1}}+g_{m_{2}}\right)+V_{\mathrm{CC}}\left(s C_{g s_{1}}+s C_{g s_{3}}\right) \\
& =V_{\mathrm{CC}}\left(g_{m_{1}}+g_{m_{2}}+s C_{g s_{1}}+s C_{g s_{3}}\right) .
\end{aligned}
$$

At the reference point,

$$
I_{i_{1}}=I_{\text {out }}
$$

Therefore,

$$
\begin{aligned}
& \left(V_{\mathrm{in}}-V_{\mathrm{CC}}\right) s\left(C_{g d_{2}}+C_{g d_{3}}\right) \\
& \quad=V_{\mathrm{CC}}\left(g_{m_{1}}+g_{m_{2}}+s C_{g s_{1}}+s C_{g s_{3}}\right) .
\end{aligned}
$$

So,

$$
\begin{aligned}
Y_{\text {in }} & =\frac{I_{\text {in }}}{V_{\text {in }}} \\
& =\left(\rho g_{m_{1}}+\rho g_{m_{2}}+g_{m_{3}}\right)+s\left(\rho C_{g s_{1}}+C_{g s_{2}}+\rho C_{g s_{3}}\right) \\
& =G_{a c}+s C_{a c}=\frac{1}{R_{\text {neg }}}+s C_{a c} .
\end{aligned}
$$

From (7) expressing the negative resistance is controlled by the transconductance $g_{m_{1}}$, transconductance $g_{m_{2}}$, and transconductance $g_{m_{3}}$ and the capacitance is determined by the gate-to-source capacitance of NMOS transistors. Adjusting these parameters will produce different negative resistance and capacitance values, which can be used to compensate the resistive loss of inductor. 


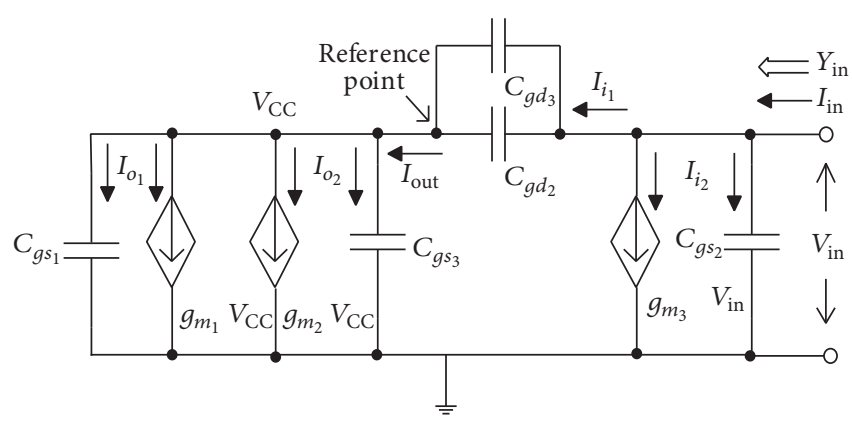

FIGURE 2: The small signal modal of active capacitor.

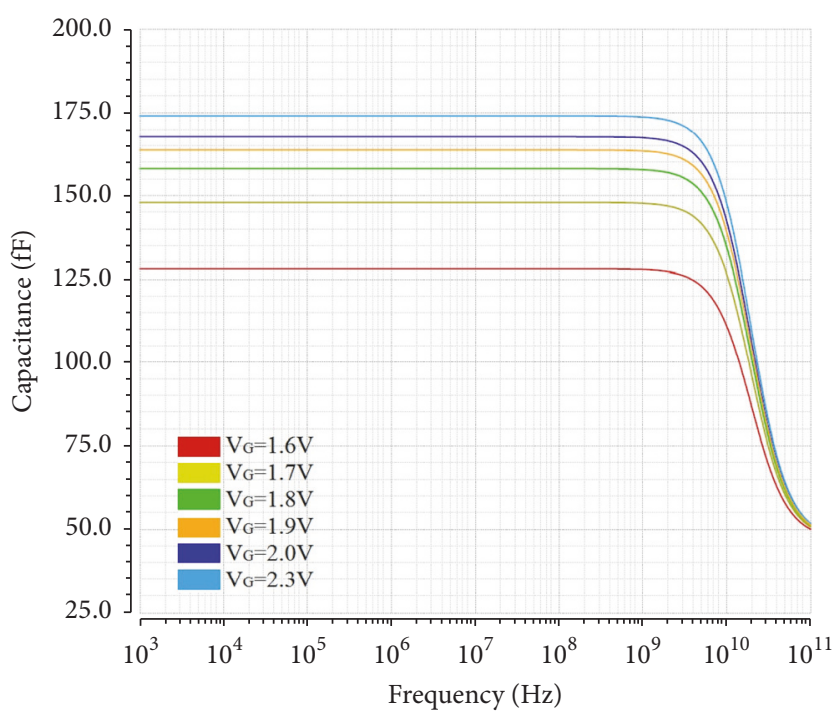

Figure 3: Tunable AC capacitance.

2.3. AC Simulations. Figures 3 and 4 unfold the fact that tuning $V_{G}$ (from $1.6 \mathrm{~V}$ to $2.3 \mathrm{~V}$ ) produces different capacitance values (from $128 \mathrm{fF}$ to $175 \mathrm{fF}$ ) and negative resistance values (from $-183 \Omega$ to $-338 \Omega$ ). For our applications, increasing $V_{G}$ will increase the capacitance value and decreases the negative resistance value. In the meantime, both capacitance and negative resistance values are stable and almost constant in a specific frequency range. For example, when $V_{G}$ varies from $1.6 \mathrm{~V}$ to $1.7 \mathrm{~V}$, the capacitance increases from $128 \mathrm{fF}$ to $148 \mathrm{fF}$ and the negative resistance decreases from $-338 \Omega$ to $-228 \Omega$ (i.e., the corresponding negative conductance increases from $-2.96 \mathrm{mS}$ to $-4.38 \mathrm{mS}$ ). The capacitance and negative resistance values are stable and constant in $3,859 \mathrm{MHz}$ and $2,486 \mathrm{MHz}$ frequency range, respectively.

\section{Tunable Active Inductor in BPF}

3.1. Gyrator-C Active Inductor (AI). Several active inductors have been proposed $[4,9-18]$. Most are designed on the

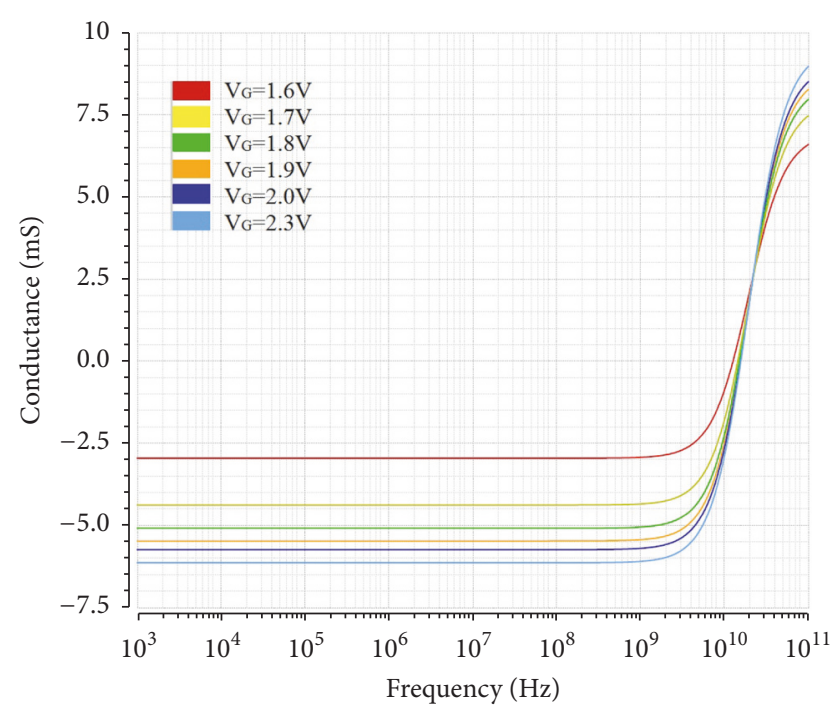

FIgURE 4: Tunable AC negative resistance.

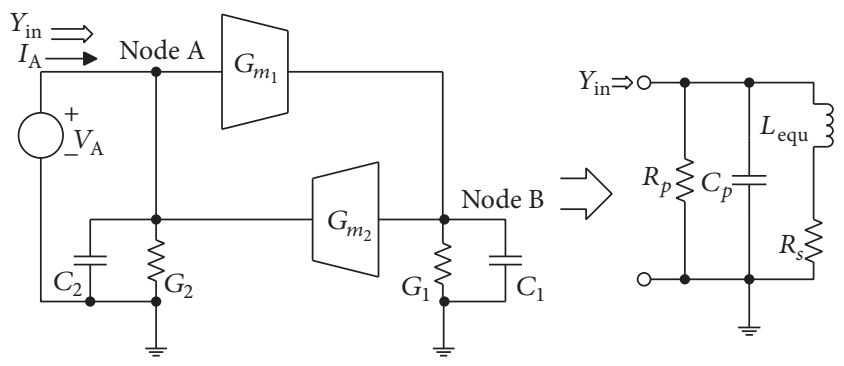

FIgURE 5: Lossy single-ended gyrator-C active inductor.

basis of the gyrator-C topology: (1) single-ended active inductors [9-13] and (2) differential active inductors [14-17]. A lossy single-ended gyrator-C active inductor is presented in Figure 5 to demonstrate how its structure performs an inductive function without use of any spiral inductors. The proposed active inductor is shown in Figure 6. Its structure is on the basis of the single-ended gyrator- $\mathrm{C}$ and its 


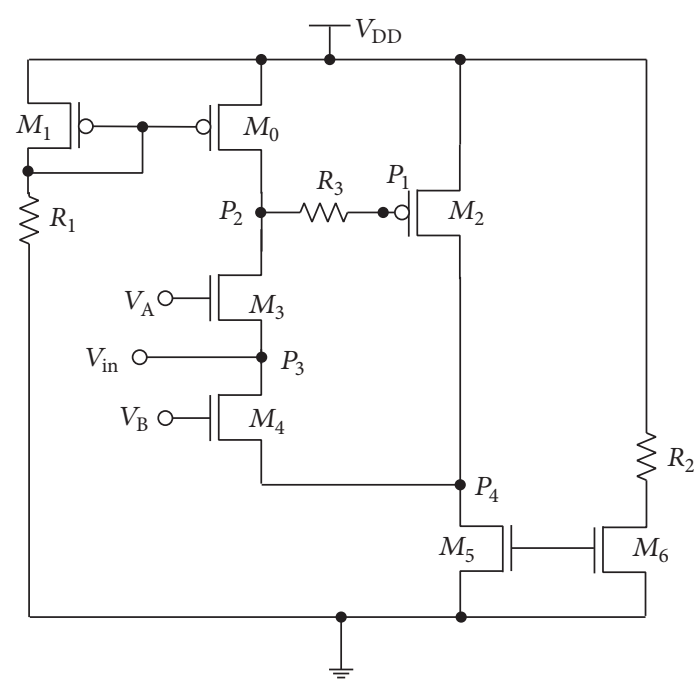

FIgURE 6: The active inductor.

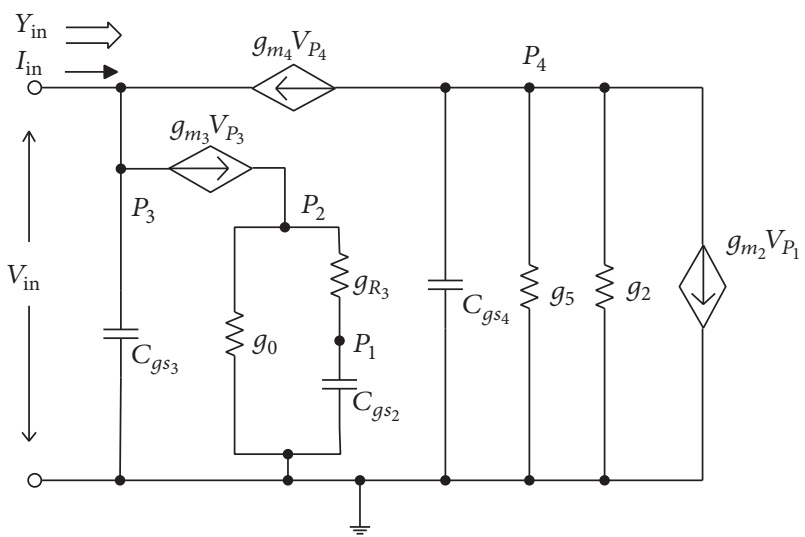

Figure 7: The small signal modal of active inductor.

tunable active inductor [4]. Figure 7 shows its small signal model.

In Figure 5, $G_{m_{1}}$ and $G_{m_{2}}$ are the transconductance. $G_{1}$ and $G_{2}$ are the total conductance at nodes B and A, respectively. So, $1 / G_{1}$ is the sum of the output impedance of $G_{m_{1}}$ and the input impedance of $G_{m_{2}}$. Similarly, $1 / G_{2}$ is the sum of the output impedance of $G_{m_{2}}$ and the input impedance of $G_{m_{1}} . C_{1}$ and $C_{2}$ are the total capacitance at nodes B and A, respectively.

At node A,

$$
-G_{m_{1}} V_{\mathrm{A}}+V_{\mathrm{B}}\left(s C_{1}+G_{1}\right)=0 .
$$

At node $B$,

$$
-G_{m_{2}} V_{\mathrm{B}}+V_{\mathrm{A}}\left(s C_{2}+G_{2}\right)-I_{\mathrm{A}}=0 .
$$

From node $\mathrm{A}$, the input impedance equals

$$
\begin{aligned}
Y_{\text {in }} & =\frac{I_{\mathrm{A}}}{V_{\mathrm{A}}} \\
& =G_{2}+s C_{2}+\frac{1}{s\left(C_{1} / G_{m_{1}} G_{m_{2}}\right)+G_{1} / G_{m_{1}} G_{m_{2}}} .
\end{aligned}
$$

Compared with the simplified model of RLC circuit,

$$
\begin{aligned}
R_{p} & =\frac{1}{G_{2}}, \\
C_{p} & =C_{2}, \\
L_{\text {equ }} & =\frac{C_{1}}{G_{m_{1}} G_{m_{2}}}, \\
R_{s} & =\frac{G_{1}}{G_{m_{1}} G_{m_{2}}} .
\end{aligned}
$$

3.2. Signal Analysis of AI. Two pairs of current mirrors $\left(M_{0}, M_{1}\right)$ and $\left(M_{5}, M_{6}\right)$ are used in Figure 6. Both gate voltages of $M_{0}$ and $M_{5}$ are controllable by tuning $R_{1}, R_{2}, M_{1}$, and $M_{6}$, which controls current of $M_{0}$ and $M_{5} . M_{2}, M_{3}$, and $M_{4}$ control small signal parameters like $g_{m_{2}}, g_{m_{3}}, g_{m_{4}}, C_{g s_{2}}$, and $\mathrm{C}_{g s_{4}}$.

For the small signal model of the proposed active inductor, the input impedance equals

$$
\begin{aligned}
Y_{\text {in }} & =\frac{I_{\text {in }}}{V_{\text {in }}}=C_{g s_{3}} s+g_{m_{3}} \\
& +\frac{g_{m_{2}} g_{m_{3}} g_{m_{4}} g_{R_{3}}}{\left(C_{g s_{4}} s+g_{m_{4}}+g_{2}+g_{5}\right)\left[\left(g_{0} C_{g s_{2}}+g_{R_{3}} C_{g s_{2}}\right) s+g_{R_{3}} g_{0}\right]}, \\
Y_{\text {in }} & =C_{g s_{3}} s+g_{m_{3}}+Y_{\text {ins }} .
\end{aligned}
$$

$Y_{\text {ins }}$ is extracted from (13):

$$
\begin{aligned}
& Y_{\text {ins }} \\
& =\frac{g_{m_{2}} g_{m_{3}} g_{m_{4}} g_{R_{3}}}{\left(C_{g s_{4}} s+g_{m_{4}}+g_{2}+g_{5}\right)\left[\left(g_{0} C_{g s_{2}}+g_{R_{3}} C_{g s_{2}}\right) s+g_{R_{3}} g_{0}\right]} .
\end{aligned}
$$

Assume $g_{7}=g_{2}+g_{5}$

$$
\begin{aligned}
Z_{\text {ins }} & =\frac{1}{Y_{\text {ins }}}=\frac{C_{g s_{4}} C_{g s_{2}}\left(g_{0}+g_{R_{3}}\right) s^{2}+\left[g_{0} g_{R_{3}} C_{g s_{4}}+\left(g_{m_{4}}+g_{7}\right)\left(g_{0}+g_{R_{3}}\right) C_{g s_{2}}\right] s+\left(g_{m_{4}}+g_{7}\right) g_{0} g_{R_{3}}}{g_{m_{2}} g_{m_{3}} g_{m_{4}} g_{R_{3}}}, \\
Z_{\text {ins }}(j \omega) & =R_{s}+j \omega L_{\text {equ }} .
\end{aligned}
$$




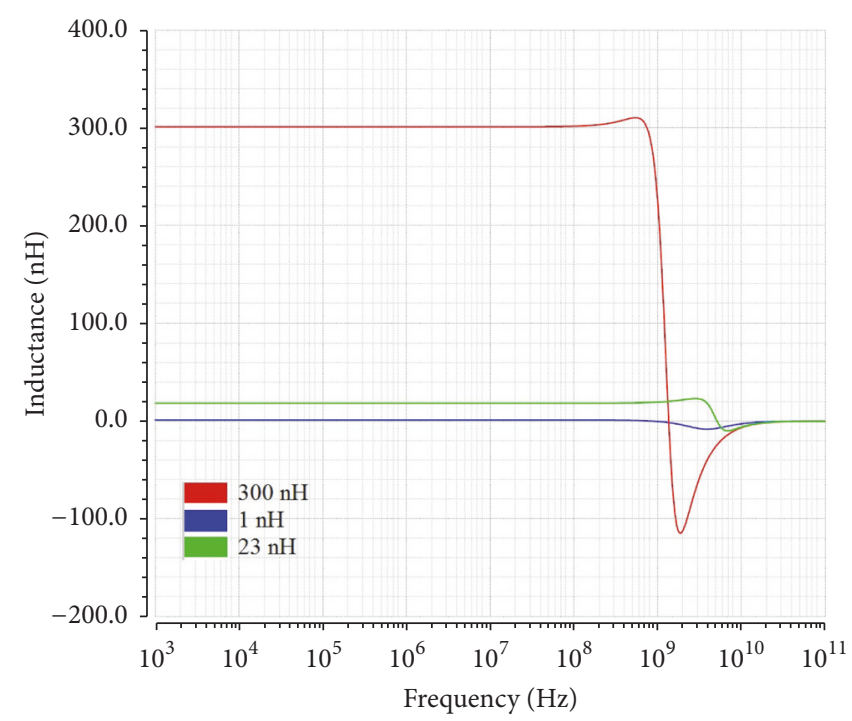

FIGURE 8: Inductance of tunable AI.

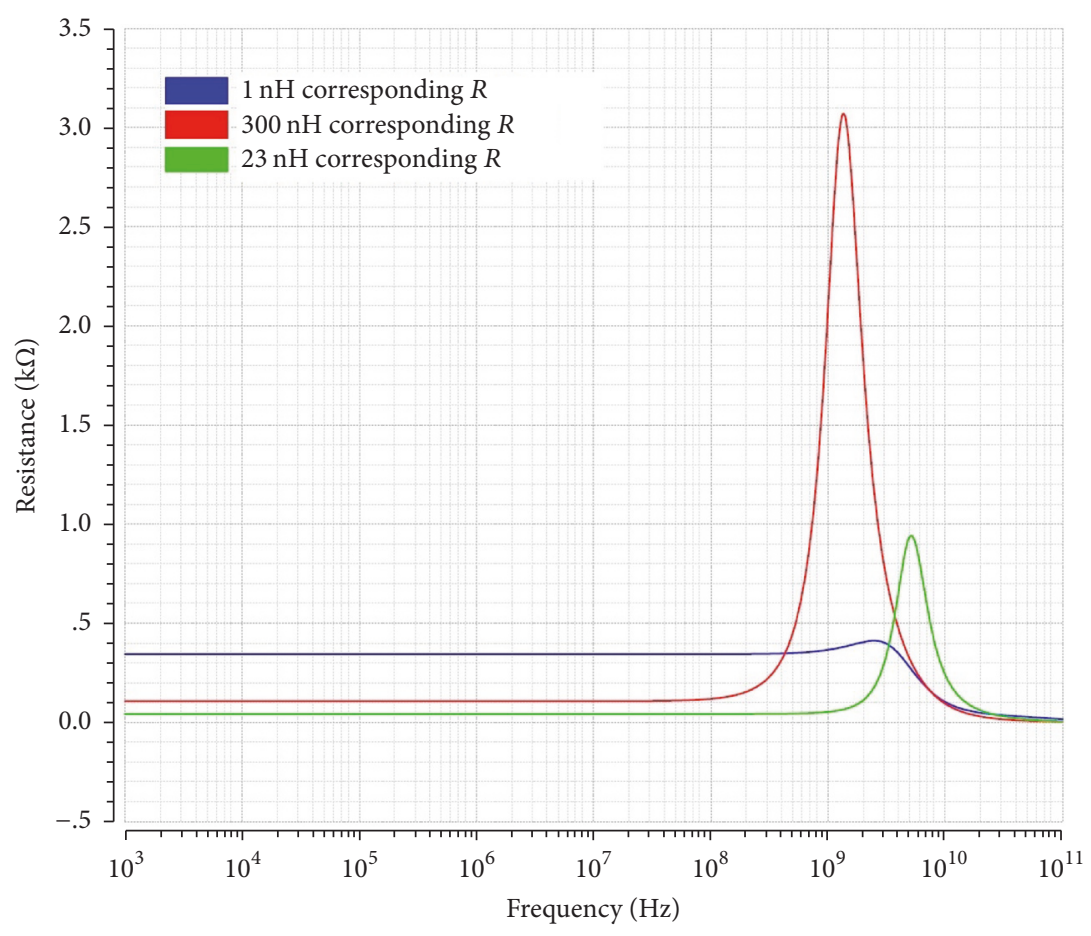

Figure 9: Resistance of tunable AI.

So,

$$
\begin{aligned}
R_{s} & =\frac{\left(g_{m_{4}}+g_{7}\right) g_{0} g_{R_{3}}-C_{g s_{4}} C_{g s_{2}}\left(g_{0}+g_{R_{3}}\right) \omega^{2}}{g_{m_{2}} g_{m_{3}} g_{m_{4}} g_{R_{3}}}, \\
L_{\text {equ }} & =\frac{\left(g_{m_{4}}+g_{7}\right)\left(g_{0}+g_{R_{3}}\right) C_{g s_{2}}+g_{0} g_{R_{3}} C_{g s_{4}}}{g_{m_{2}} g_{m_{3}} g_{m_{4}} g_{R_{3}}} .
\end{aligned}
$$

Compared with the simplified model in Figure 5, it is shown that $R_{p}=1 / g_{m_{3}}$ and $C_{p}=C_{g s_{3}}$.
From the above analysis, $L_{\text {equ }}$ and $R_{s}$ are functions of $g_{m_{2}}$, $g_{m_{3}}, g_{m_{4}}, g_{0}, g_{7}, g_{R_{3}}, C_{g_{2}}$, and $C_{g_{s_{4}}}$. Both are controllable by changing the large signal bias conditions as discussed in this section.

3.3. AI Simulations. Figures 8 and 9 show inductance and resistance values by tuning the DC bias voltage. The inductance varies from 1 to $300 \mathrm{nH}$ and resistance varies from 43 to $344 \Omega$. As shown in the plot, the highest inductive frequency range is achieved at $5,156 \mathrm{MHz}$ with a peak inductance of 


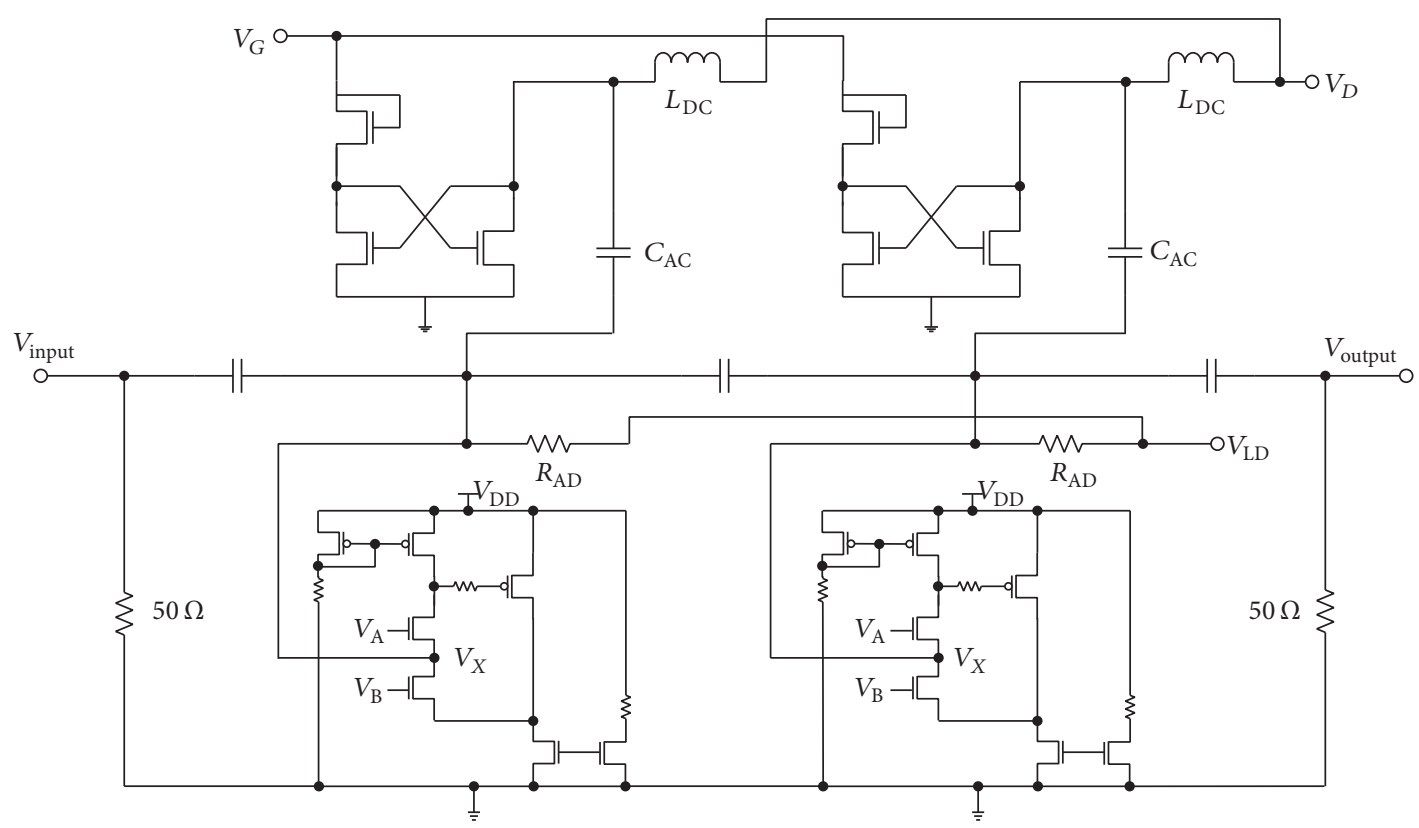

FIGURE 10: The proposed tunable BPF.

$23 \mathrm{nH}$. By means of adjusting the bias conditions, different inductance and resistance values can be produced for different applications in a specific inductive frequency range. Figure 9 shows the tunable resistance. For example, when the active inductance value is adjusted from $1 \mathrm{nH}$ to $300 \mathrm{nH}$, the resistance value changes from $344 \Omega$ to $107 \Omega$ and the frequency range is from $275 \mathrm{MHz}$ to $770 \mathrm{MHz}$.

\section{Chebyshev BPF Using Active Capacitor and Inductor}

4.1. Design. The 2nd-order active BPF is designed based on the classic Chebyshev BPF structure [19-21]. The Chebyshev $\mathrm{BPF}$ has inferior selectivity due to the poor stopband rejection level. To improve selectivity in wide bandwidth, techniques of introducing transmission zeros to increase stopband by adding shunt capacitor, serial inductor, or shunt inductor have been presented [22-25]. The active BPF proposed in this research is shown in Figure 10. Two resonators are designed using active capacitor and active inductor in which the negative resistance of active capacitor compensates the resistive loss of active inductor as shown in Figure 11. The resistance compensation is optimized at the center frequency of $758 \mathrm{MHz}$. It achieves a gain of $18.1 \mathrm{~dB}$, a $Q$ factor of 107 , and a stopband rejection of $50 \mathrm{~dB}$. The BPF performance is shown in Figure 12. In Figure 10, $L_{\mathrm{DC}}$ is added to produce the DC bias voltage and block the AC signal; $C_{\mathrm{AC}}$ is added to bypass the AC signal and block the DC current. Figure 13 depicts capacitance versus frequency (before and after using $L_{\mathrm{DC}}$ and $C_{\mathrm{AC}}$ ). Figure 14 depicts conductance versus frequency (before and after using $L_{\mathrm{DC}}$ and $C_{\mathrm{AC}}$ ). As shown in Figures 13 and 14 , after adding $L_{\mathrm{DC}}$ and $C_{\mathrm{AC}}$, the capacitance and negative conductance values are stable and almost constant in the frequency range [758 MHz, $864 \mathrm{MHz}$. In Figure 10, after applying a DC supply voltage $V_{\mathrm{LD}}$ and a resistor $R_{\mathrm{AD}}$, a DC bias voltage $(0.9 \mathrm{~V})$ is obtained at $V_{X}$. Figure 15 depicts inductance versus frequency (before and after using $R_{\mathrm{AD}}$ ) and Figure 16 shows resistance versus frequency (before and after using $R_{\mathrm{AD}}$ ).

As shown in Figures 15 and 16, after adding $R_{\mathrm{AD}}$, the inductance and its positive resistance are slightly changed. The reason is explained below. From the analysis of the small signal equivalent model in Figure $11, L_{\mathrm{DC}}, C_{0}$, and $R_{\mathrm{neg}_{0}}$ constitute a RLC parallel circuit.

In Figure 11(b), the admittance of this RLC parallel circuit equals

$$
\begin{aligned}
Y_{\text {inp }} & =\frac{I_{\text {in }}}{V_{\text {in }}}=\frac{1}{R_{\mathrm{neg}_{0}}}+j \omega C_{0}+\frac{1}{j \omega L_{\mathrm{DC}}} \\
& =\frac{1}{R_{\mathrm{neg}_{0}}}+j\left(\omega C_{0}-\frac{1}{\omega L_{\mathrm{DC}}}\right) .
\end{aligned}
$$

If $L_{\mathrm{DC}}$ is large enough, $\frac{1}{\omega L_{\mathrm{DC}}}$ can be neglected. In Figure 11(c), if $C_{\mathrm{AC}}$ is large enough, then

$$
\begin{aligned}
C_{\text {equ }} & =\frac{C_{\mathrm{AC}} C_{1}}{C_{\mathrm{AC}}+C_{1}}, \\
R_{\text {neg }_{\text {equ }}} & =\left(1+\frac{C_{1}}{C_{\mathrm{AC}}}\right) R_{\text {neg }_{1}} .
\end{aligned}
$$

It means the effect of $C_{\mathrm{AC}}$ can be neglected. On the other hand, $L_{\mathrm{DC}}$ and $C_{\mathrm{AC}}$ do not take part in the performance of BPF.

By adjusting $R_{\mathrm{AD}}$, the input $\mathrm{DC}$ voltage of the active inductor can be adjusted to a desirable bias value accordingly. $R_{\mathrm{AD}}$ is in parallel with $L_{\mathrm{AI}_{0}}$ and $R_{\mathrm{S}_{0}}$. Giving a large $R_{\mathrm{AD}}, L_{\mathrm{AI}_{1}} \approx$ $L_{\mathrm{AI}_{0}}$ and $R_{S_{1}} \approx R_{S_{0}}$, as shown in Figure 11(c). 

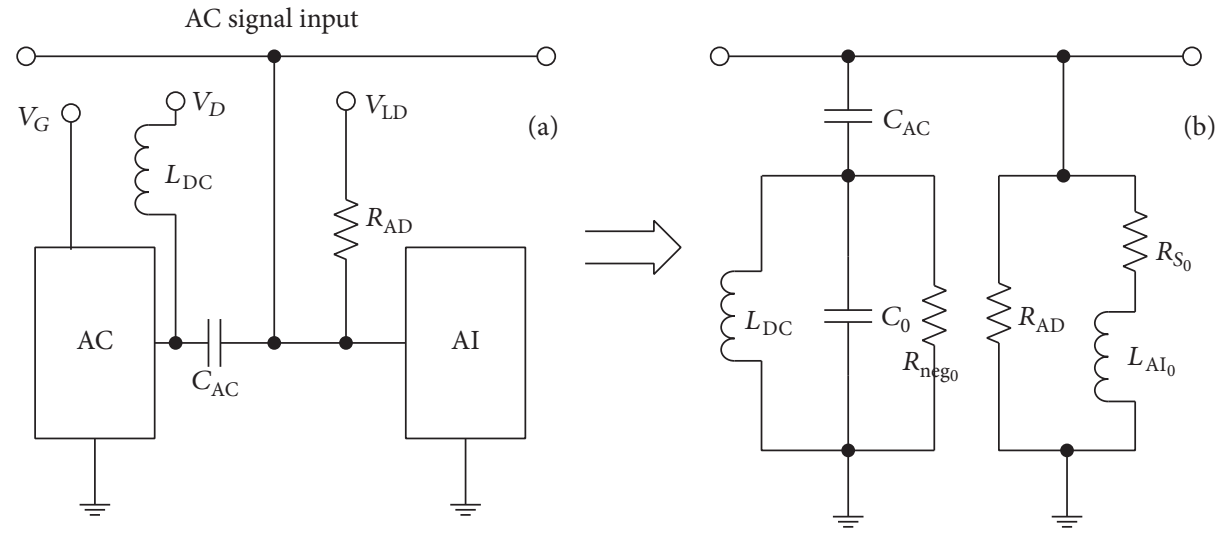

(b)

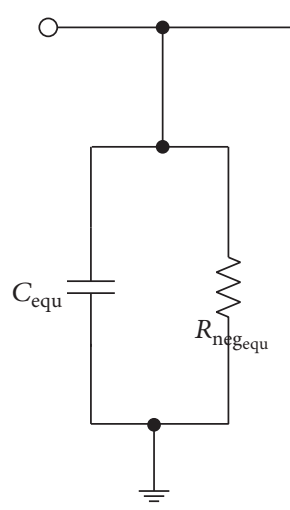

(d)

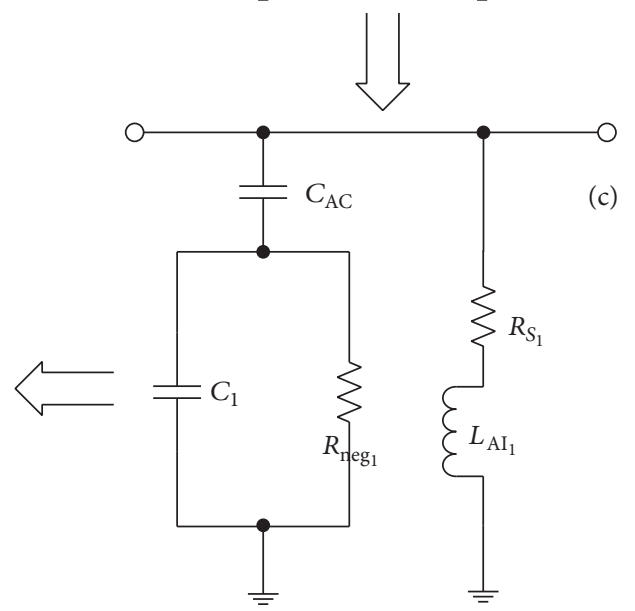

FIGURE 11: Equivalent circuits of the resonator.

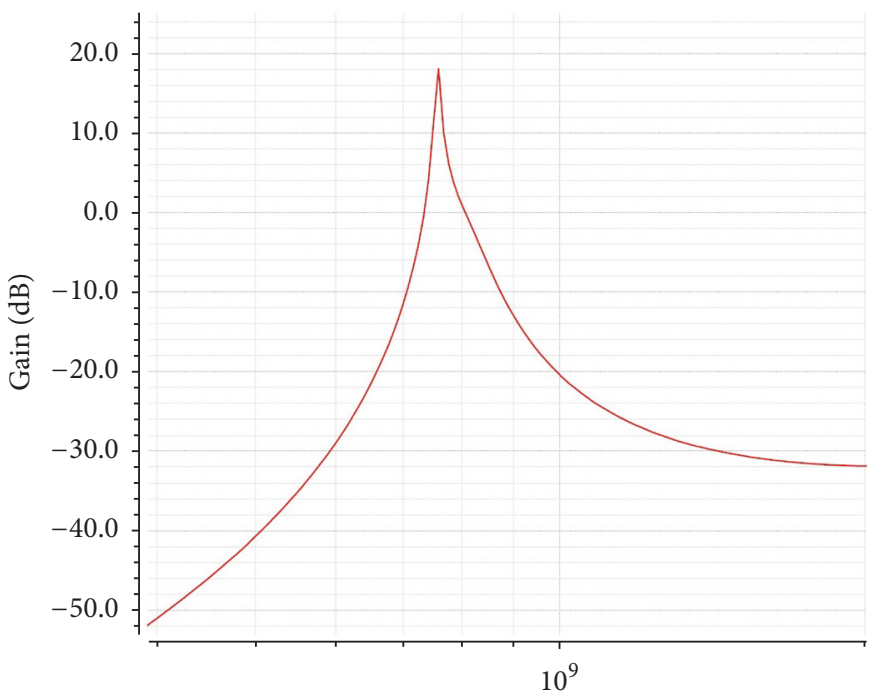

Frequency $(\mathrm{Hz})$

FIGURE 12: BPF performance. 


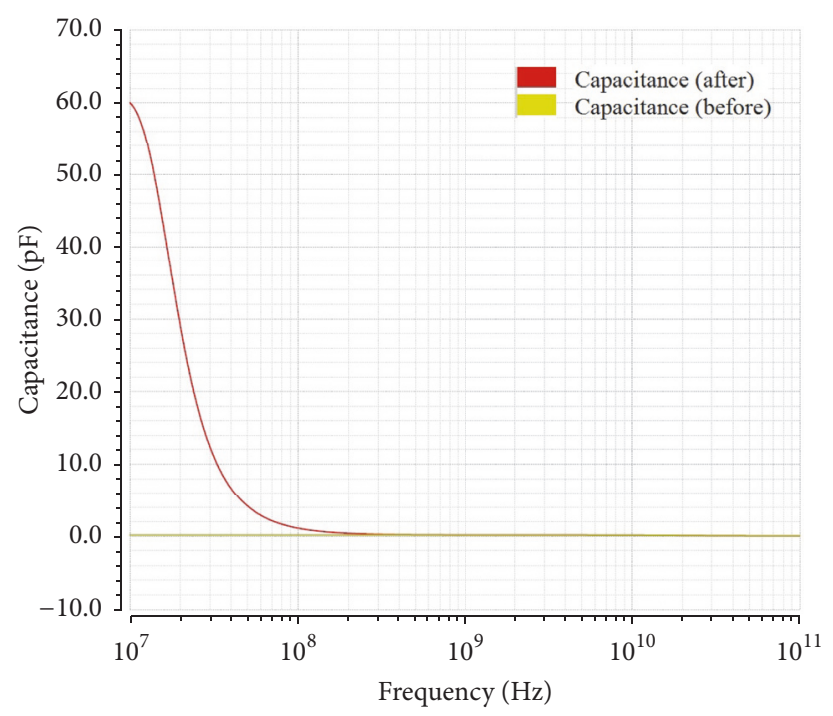

Figure 13: Capacitance versus frequency (before and after using $L_{\mathrm{DC}}$ and $C_{\mathrm{AC}}$ ).

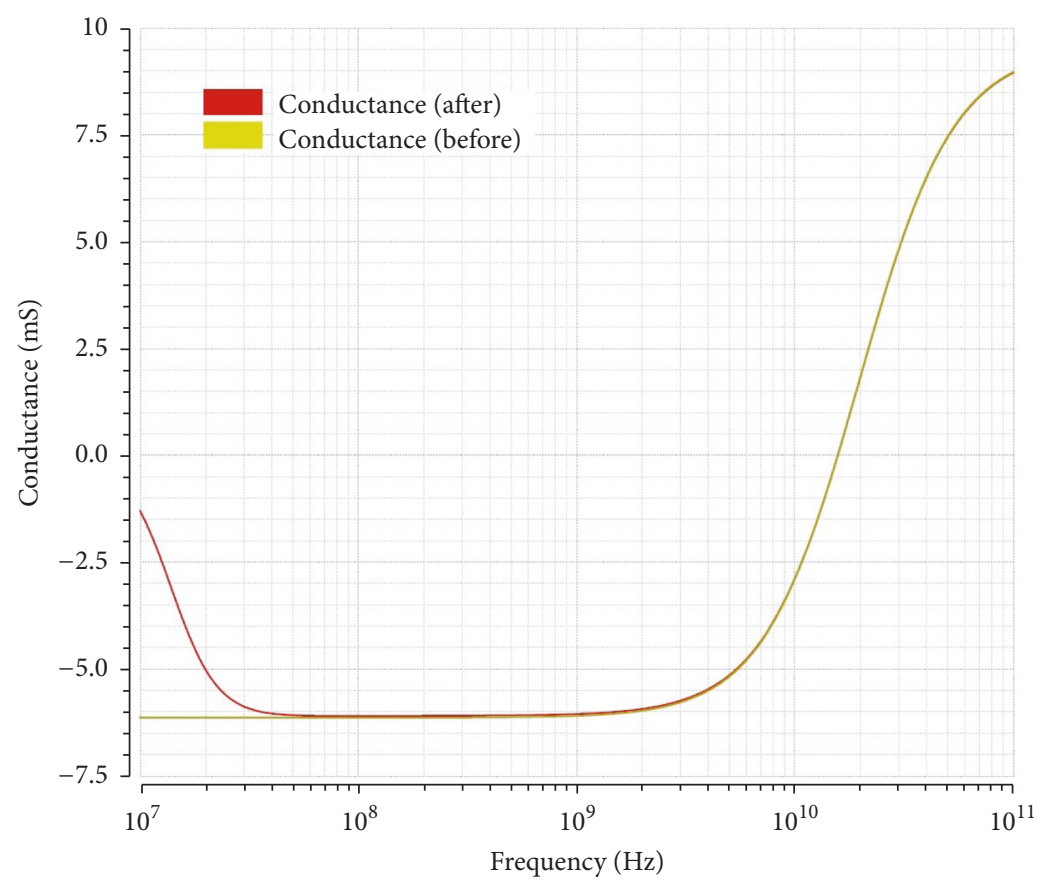

FIgURE 14: Conductance versus frequency (before and after using $L_{\mathrm{DC}}$ and $C_{\mathrm{AC}}$ ).

In order to find a match between the negative resistance and the positive resistance, $L_{\mathrm{AI}}$ in series with $R_{S_{1}}$ is changed to $R_{p}$ in parallel with $L_{\text {equ }}$ where $Q$ is quality factor of the active inductor.

$$
\begin{gathered}
R_{p}=\left(1+Q^{2}\right) R_{S_{1}}, \\
L_{\text {equ }}=\left(1+\frac{1}{Q^{2}}\right) L_{\mathrm{AI}_{1}},
\end{gathered}
$$

$$
\begin{aligned}
\omega_{0} & =\frac{1}{\sqrt{L_{\text {equ }} C_{\text {equ }}}}, \\
R_{\text {neg }_{\text {equ }}} & =R_{p} .
\end{aligned}
$$

4.2. Performance Evaluation. The active inductor in this application provides a relative fixed value of inductance and resistance. By adjusting the bias voltage $V_{G}$, a tunable 


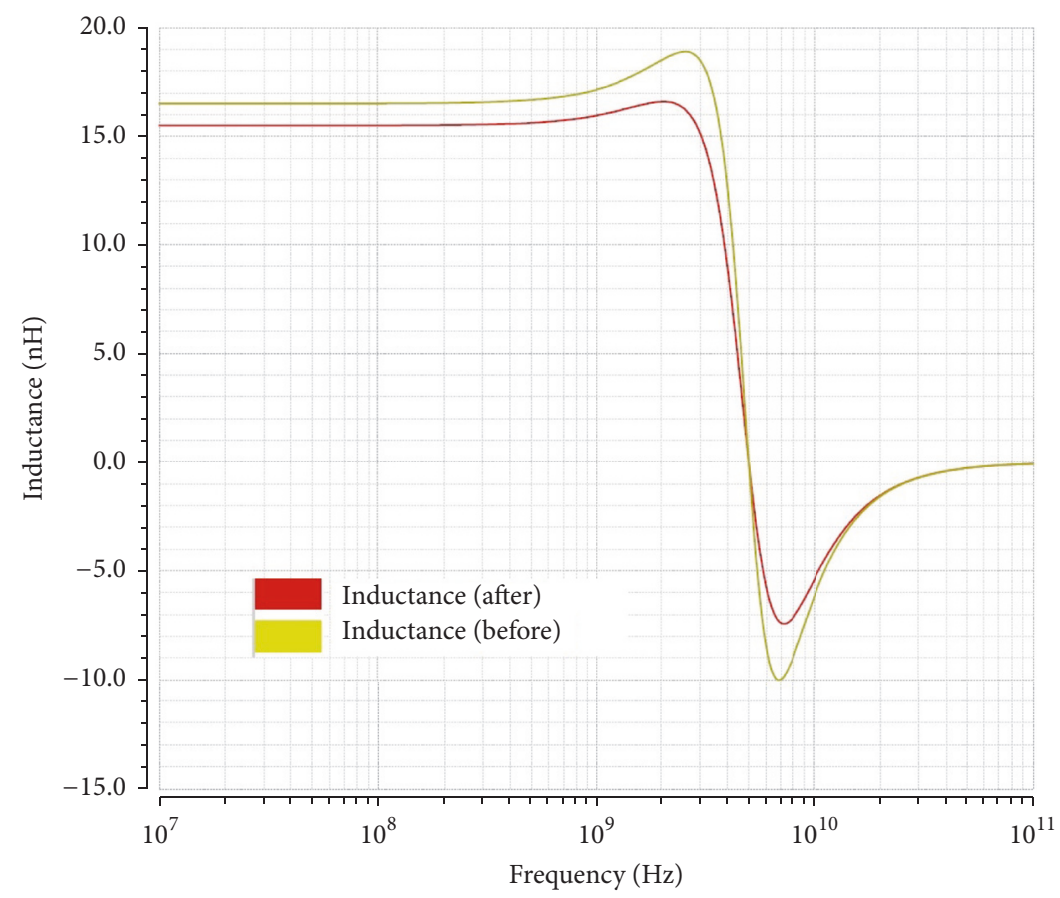

FIGURE 15: Inductance versus frequency (before and after using $R_{\mathrm{AD}}$ ).

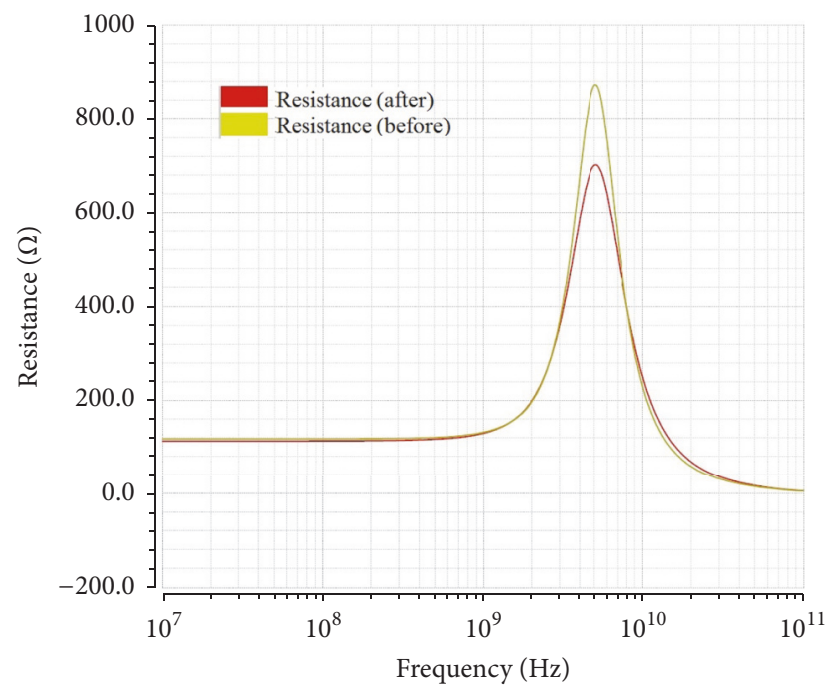

FIGURE 16: Resistance versus frequency (before and after using $R_{\mathrm{AD}}$ ).

capacitance of the active capacitor is obtained, which makes this BPF tunable. Figure 17 displays the BPF tunability for the center frequency [ $758 \mathrm{MHz}, 864 \mathrm{MHz}$ ], the $3 \mathrm{~dB}$ bandwidth [7.1 MHz, 65.9 MHz], the gain [6.5 dB, $18.1 \mathrm{~dB}]$, the stopband rejection $[38 \mathrm{~dB}, 50 \mathrm{~dB}]$, and the quality factor $[12,107]$.

It is observed from Figure 17 that when $V_{G}$ is decreased (from the lower bound to the upper bound), the gain is decreased, and the $3 \mathrm{~dB}$ bandwidth is increased. At the center frequency of $758 \mathrm{MHz}$ (red plot), the resistance loss of the active inductor is nearly cancelled by the negative resistance of the active capacitor, leading to an ideal resonator in the circuit.

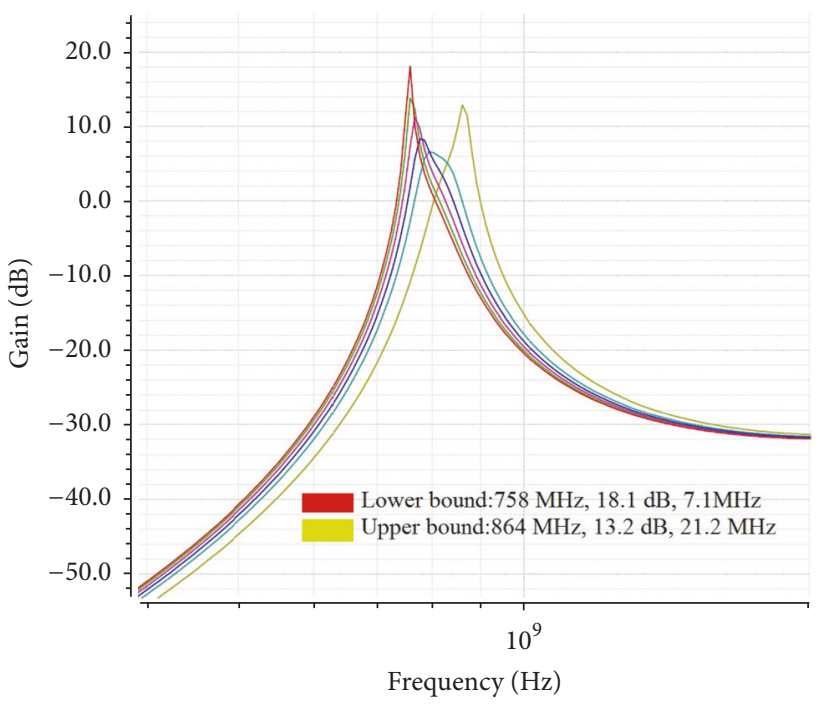

FIGURE 17: Tunable BPF gain versus signal freq.

Table 1 presents detailed analysis of six BPF center frequency cases $(758 \mathrm{MHz}, 770 \mathrm{MHz}, 778 \mathrm{MHz}, 800 \mathrm{MHz}$, $844 \mathrm{MHz}$, and $864 \mathrm{MHz}$ ) in Figure 17. In the active inductor column, $L_{\mathrm{AI}_{1}}, R_{\mathrm{S}_{1}}$, and $Q_{\mathrm{AI}}$ are the BPF design values; $L_{\text {equ }}$ and $R_{p}$ are the analysis values calculated from (19) and (20). In the active capacitor column, $R_{\text {neg }_{\text {equ }}}$ and $C_{\text {equ }}$ are the BPF design values. Applying the $L_{\text {equ }}$ and $C_{\text {equ }}$ values, the theoretical center frequency $f_{0}$ is then calculated from (21). The BPF column presents quality factor, pass band gain, and bandwidth. By comparing the theoretical $f_{0}$ and the measured $f_{0}$ the error percentage $\Delta f_{0}$ is about $1 \%$. By 


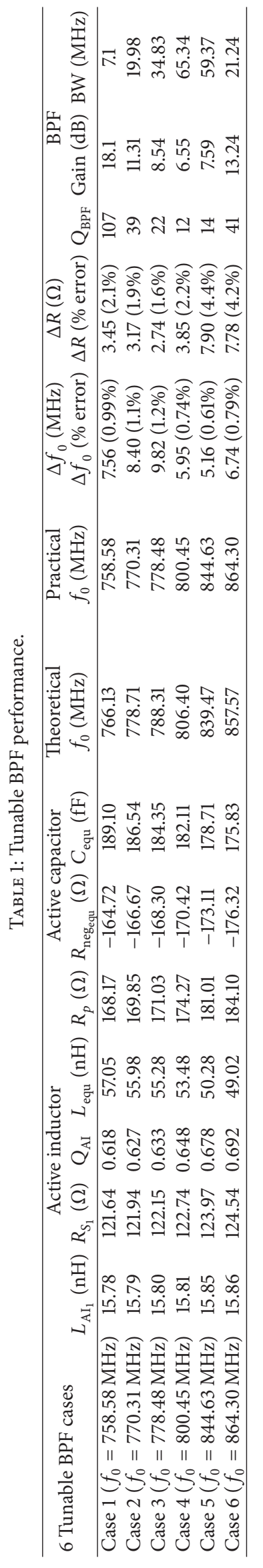


TABLE 2: The previously reported several works by using the same structure of classic Chebyshev bandpass filter.

\begin{tabular}{|c|c|c|c|c|c|c|c|}
\hline & {$[1]$} & [2] & {$[5]$} & [6] & [7] & {$[8]$} & This work \\
\hline Technology process & $\begin{array}{l}\text { CMOS } \\
0.18 \mu \mathrm{m}\end{array}$ & $\begin{array}{l}\text { CMOS } \\
0.18 \mu \mathrm{m}\end{array}$ & $\begin{array}{c}\text { BJT } \\
\text { BFP420 }\end{array}$ & $\begin{array}{c}\text { BJT } \\
\text { BFR92A }\end{array}$ & $\begin{array}{c}\text { BJT } \\
\text { BFR92A }\end{array}$ & $\begin{array}{l}\text { CMOS } \\
0.18 \mu \mathrm{m}\end{array}$ & $\begin{array}{c}\text { CMOS } \\
0.18 \mu \mathrm{m}\end{array}$ \\
\hline Active component & $\begin{array}{c}\text { Active } \\
\text { capacitor }\end{array}$ & - & $\begin{array}{l}\text { Active } \\
\text { inductor }\end{array}$ & $\begin{array}{l}\text { Active } \\
\text { inductor }\end{array}$ & $\begin{array}{l}\text { Active } \\
\text { inductor }\end{array}$ & - & $\begin{array}{c}\text { Active } \\
\text { capacitor/inductor }\end{array}$ \\
\hline Order & 2 & 2 & 3 & 2 & 1 & 3 & 2 \\
\hline Center frequency $(\mathrm{MHz})$ & 5300 & 23500 & 1950 & 2100 & 600 & 2368 & 758 \\
\hline $\mathrm{BW}(\mathrm{MHz})$ & 1700 & 4000 & 10 & 15 & 300 & 60 & 7.1 \\
\hline Pass band gain $(\mathrm{dB})$ & 0.77 & 1.65 & -8 & 0 & 0.1 & 1.8 & 18.1 \\
\hline Stopband rejection $(\mathrm{dB})$ & 36.8 & 15.2 & - & - & - & 30 & 50 \\
\hline Power $(\mathrm{mW})$ & 2.2 & 4.2 & 4 & - & 120 & 8.8 & 25.5 \\
\hline Quality factor & 3 & 6 & 195 & 140 & 2 & 40 & 107 \\
\hline \multicolumn{8}{|l|}{ Tunability } \\
\hline Center freq. (MHz) & - & - & $1800 \sim 2050$ & - & - & - & $758 \sim 864$ \\
\hline Gain $(\mathrm{dB})$ & - & - & -8 & - & - & - & $6.5 \sim 18.1$ \\
\hline $\mathrm{BW}(\mathrm{MHz})$ & - & - & 10 & - & - & - & 7.1 65.9 \\
\hline Quality factor & - & - & $180 \sim 205$ & - & - & - & $12 \sim 107$ \\
\hline
\end{tabular}

comparing the analysis value $R_{p}$ and the design value $R_{\text {neg }_{\text {equ }}}$ the error percentage $\Delta R$ is less than $5 \%$, which shows that the resistive loss of active inductor is almost cancelled by negative resistance of active capacitor.

Table 2 summarizes this and past work of classic Chebyshev bandpass filter. As shown in this table, the pass band gain, stopband rejection, and quality factor of the tunable BPF are much higher than those of most of the other works.

\section{Conclusion}

In this paper, a classic Chebyshev BPF adopting active capacitor and active inductor for tunability, low cost, and smaller size is presented. The tunability of BPF center frequency and pass band is achieved by controlling the active capacitance, which is tunable by adjusting the DC bias voltage. The negative resistance of active capacitor compensates $95 \%$ above the resistive loss of active inductor in the tunable center frequency range. A pass band gain of $18.1 \mathrm{~dB}$ and stopband rejection of $50 \mathrm{~dB}$ are obtained at the center frequency $758 \mathrm{MHz}$. The BPF achieves a high quality factor $Q$ of 12-107 and a high stopband rejection of $38-50 \mathrm{~dB}$.

\section{Conflicts of Interest}

The authors declare that there are no conflicts of interest regarding the publication of this paper.

\section{References}

[1] S. Wang and W.-J. Lin, "C-band complementary metal-oxidesemiconductor bandpass filter using active capacitance circuit," IET Microwaves, Antennas and Propagation, vol. 8, no. 15, pp. 1416-1422, 2014.
[2] S. Wang and B.-Z. Huang, "Design of low-loss and highlyselective CMOS active bandpass filter at K-Band," Progress in Electromagnetics Research, vol. 128, pp. 331-346, 2012.

[3] C.-Y. Wu and K.-N. Lai, "Integrated A-type differential negative resistance MOSFET device," IEEE Journal of Solid-State Circuits, vol. 14, no. 6, pp. 1094-1101, 1979.

[4] H. B. Kia and A. K. A'ain, "A wide tuning range voltage controlled oscillator with a high tunable active inductor," Wireless Personal Communications, vol. 79, no. 1, pp. 31-41, 2014.

[5] L. Pantoli, V. Stornelli, and G. Leuzzi, "Tunable active filters for RF and microwave applications," Journal of Circuits, Systems and Computers, vol. 23, no. 6, Article ID 1450088, 2014.

[6] V. Stornelli, L. Pantoli, and G. Leuzzi, "High quality factor Lband active inductor-based band-pass filters," Journal of Circuits, Systems and Computers, vol. 22, no. 3, Article ID 1350014, 2013.

[7] G. Leuzzi, V. Stornelli, and S. Del Re, "A tuneable active inductor with high dynamic range for band-pass filter applications," IEEE Transactions on Circuits and Systems II: Express Briefs, vol. 58, no. 10, pp. 647-651, 2011.

[8] J. Kulyk and J. Haslett, "A monolithic CMOS $236830 \mathrm{MHz}$ transformer based Q-enhanced Series-C coupled resonator bandpass filter," IEEE Journal of Solid-State Circuits, vol. 41, no. 2, pp. 362-374, 2006.

[9] L. C. Lee, A. K. A'ain, and A. V. Kordesch, "Design of CMOS tunable image-rejection low-noise amplifier with active inductor," VLSI Design, vol. 2008, 6 pages, 2008.

[10] C.-C. Hsiao, C.-W. Kuo, C.-C. Ho, and Y.-J. Chan, "Improved quality-factor of $0.18-\mu \mathrm{m}$ CMOS active inductor by a feedback resistance design," IEEE Microwave and Wireless Components Letters, vol. 12, no. 12, pp. 467-469, 2002.

[11] M. Moezzi and M. S. Bakhtiar, "Wideband LNA using active inductor with multiple feed-forward noise reduction paths," IEEE Transactions on Microwave Theory and Techniques, vol. 60, no. 4, pp. 1069-1078, 2012. 
[12] L. Pantoli, V. Stornelli, and G. Leuzzi, "Class AB tunable active inductor," Electronics Letters, vol. 51, no. 1, pp. 65-67, 2015.

[13] H.-L. Kao, P.-C. Lee, and H.-C. Chiu, "A wide tuning-range CMOS VCO with a tunable active inductor," Mathematical Problems in Engineering, vol. 2015, Article ID 382483, 2015.

[14] C. Li, F. Gong, and P. Wang, "Analysis and design of a highQ differential active inductor with wide tuning range," IET Circuits, Devices and Systems, vol. 4, no. 6, pp. 486-495, 2010.

[15] L.-H. Lu, H.-H. Hsieh, and Y.-T. Liao, "A wide tuning-range CMOS VCO with a differential tunable active inductor," IEEE Transactions on Microwave Theory and Techniques, vol. 54, no. 9, pp. 3462-3468, 2006.

[16] H. B. Kia and A. K. A'ain, "A high gain and low flicker noise CMOS mixer with low flicker noise corner frequency using tunable differential active inductor," Wireless Personal Communications, vol. 79, no. 1, pp. 599-610, 2014.

[17] M. M. Reja, I. M. Filanovsky, and K. Moez, "Wide tunable CMOS active inductor," Electronics Letters, vol. 44, no. 25, pp. 1461-1463, 2008.

[18] F. Yuan, CMOS Active Inductors and Transformers: Principle, Implementation, and Applications, Springer, New York, NY, USA, 2008.

[19] S. B. Cohn, "Direct-coupled-resonator filters," Proceedings of the IRE, vol. 45, no. 2, pp. 187-196, 1957.

[20] J. B. Ness, "A unified approach to the design, measurement, and tuning of coupled-resonator filters," IEEE Transactions on Microwave Theory and Techniques, vol. 46, no. 4, pp. 343-351, 1998.

[21] S. Hao and Q. J. Gu, "A fourth order tunable capacitor coupled microstrip resonator band pass filter," in Proceedings of the IEEE Radio and Wireless Symposium, RWS 2015-RWW 2015, pp. 150-152, San Diego, Calif, USA, January 2015.

[22] S. Wang and B.-Z. Huang, "Design of CMOS active bandpass filter with three transmission zeros," Electronics Letters, vol. 47, no. 20, pp. 1130-1131, 2011.

[23] L. K. Yeung and K.-L. Wu, "A compact second-order LTCC bandpass filter with two finite transmission zeros," IEEE Transactions on Microwave Theory and Techniques, vol. 51, no. 2, pp. 337-341, 2003.

[24] C.-F. Chang and S.-J. Chung, "Bandpass filter of serial configuration with two finite transmission zeros using LTCC technology," IEEE Transactions on Microwave Theory and Techniques, vol. 53, no. 7, pp. 2383-2388, 2005.

[25] H. Huang and T. Horng, "Design of Compact Bandpass Filter with Controllable Multiple Transmission Zeros using The Second-Order Inductive-Coupled Resonator," Microwave and Optical Technology Letters, vol. 55, no. 9, pp. 2155-2157, 2013. 


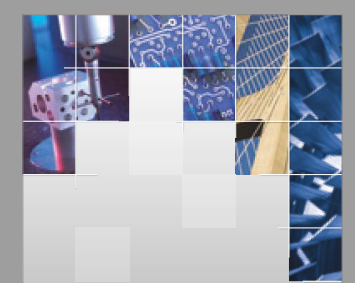

\section{Enfincering}
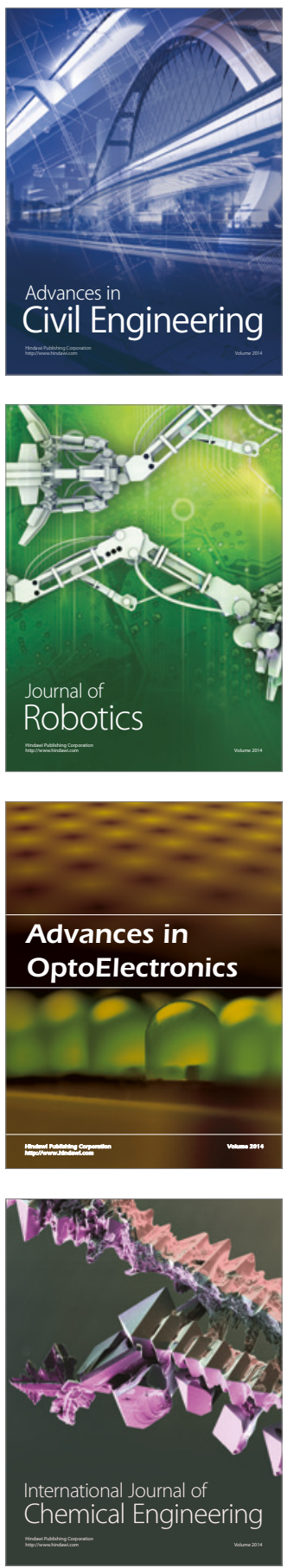

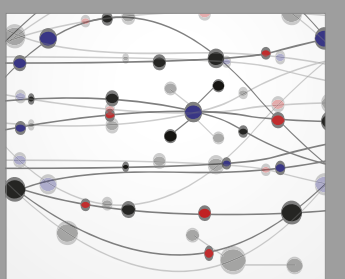

The Scientific World Journal

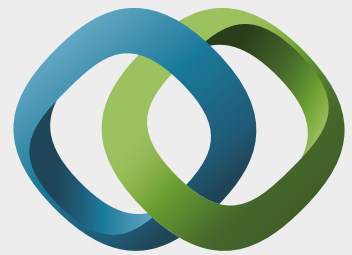

\section{Hindawi}

Submit your manuscripts at

https://www.hindawi.com
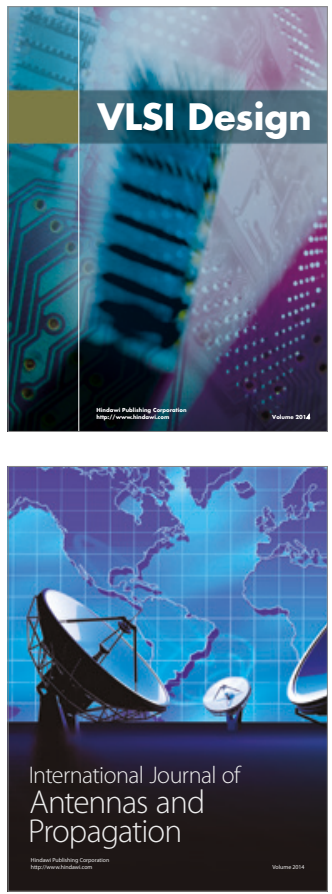

\section{Rotating}

Machinery
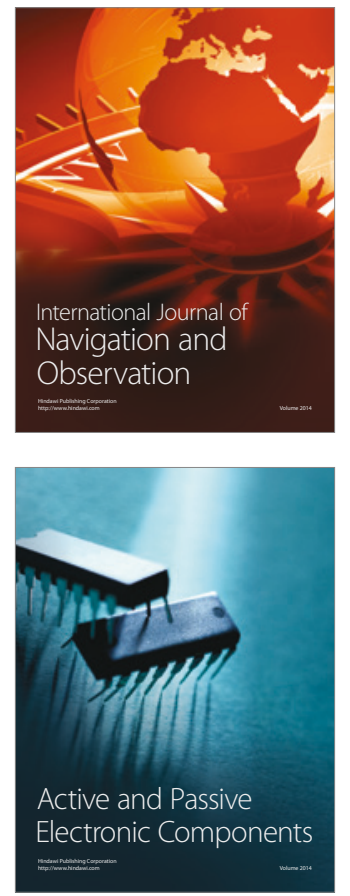
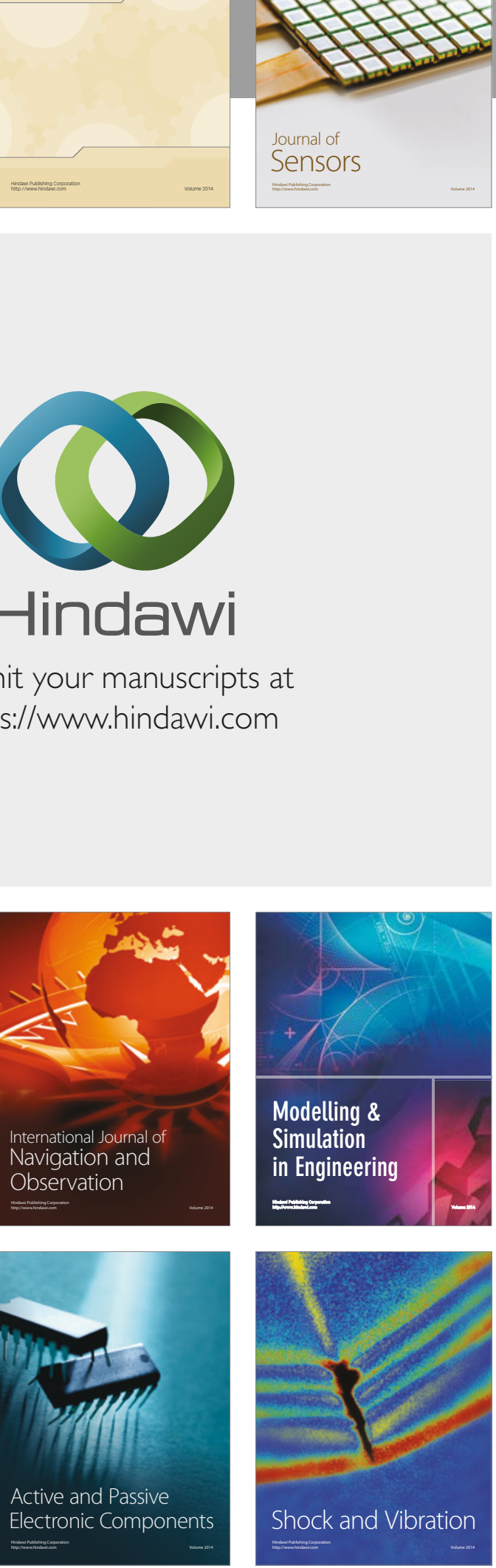
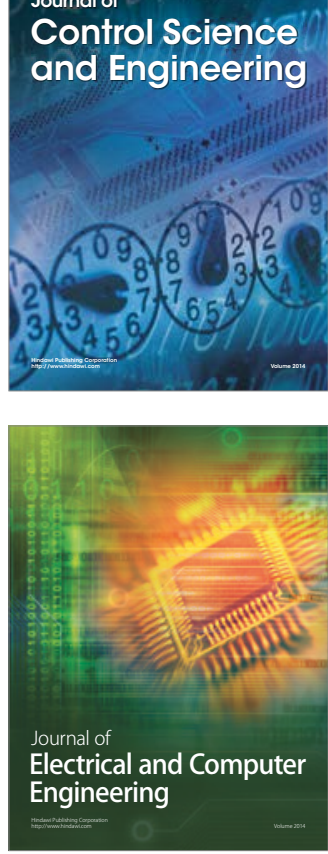

Distributed

Journal of

Control Science

and Engineering
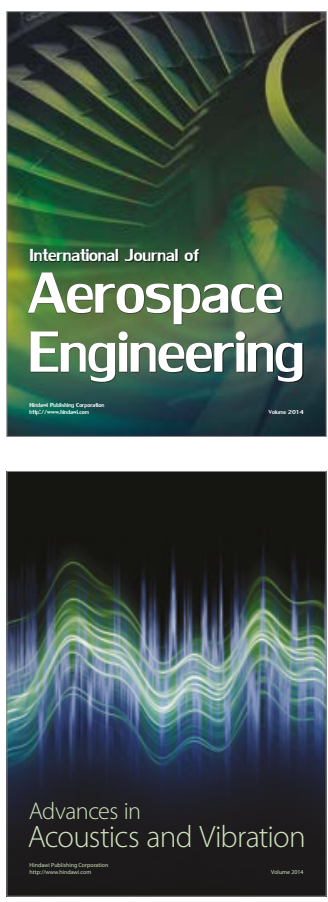

Sensor Networks 